\title{
Cognitive compatibility in modern manual mixed-model assembly systems
}

\author{
Dominic Bläsing ${ }^{1,2} \cdot$ Manfred Bornewasser ${ }^{1}$ Sven Hinrichsen ${ }^{3}$
}

Accepted: 12 November 2021 / Published online: 9 December 2021

(c) The Author(s) 2021

\begin{abstract}
The compatibility concept is widely used in psychology and ergonomics. It describes the fit between elements of a sociotechnical system which is a prerequisite to successfully cooperate towards a common goal. For at least three decades, cognitive compatibility is of increasing importance. It describes the fit of externally presented information, information processing, and the required motor action. However, with increasing system complexity, probability for incompatibility increases, too, leading to time losses, errors and overall degraded performance. The elimination of cognitive incompatibilities through ergonomic measures at the workplace requires a lot of creativity and effort. Using practical examples from mixed-model assembly, improved information management and the use of informational assistance systems are discussed as promising ergonomic approaches. The ultimate goal is to avoid cognitive overload, for example in part picking or assembly tools choosing. To find a fit between externally mediated work instructions via displays and the subjectively used internal models and competencies is a challenging task. Only if this fit is given the system is perceived as beneficial. To achieve this, the assistance system should be configurable to fit individual needs as far as possible. Successful system design requires early participation and comprehensive integration of the assistance systems into the existing IT infrastructure. Practical relevance: Varied manual assembly requires a high degree of cognitive work. A rise in complexity of the assembly task increases the risk that cognitive incompatibility and thus cognitive overload will occur more frequently. It is shown that such unhealthy conditions can be countered by better information presentation and by the use of individually adaptable informational assistance systems.
\end{abstract}

Keywords Compatibility $\cdot$ Mental model $\cdot$ Mental workload $\cdot$ Multi-model assembly $\cdot$ Informational assistance systems

Dipl. Psych. Dominic Bläsing

dominic.blaesing@med.uni-greifswald.de

1 Institut für Psychologie, Universität Greifswald, Franz-Mehring-Straße 47, 17489 Greifswald, Germany

2 Institut für Community Medicine, Abteilung für Präventionsforschung und Sozialmedizin, Universitätsmedizin Greifswald, Walther-Rathenau-Straße 48, 17489 Greifswald, Germany

3 Labor für Industrial Engineering, Technische Hochschule Ostwestfalen-Lippe, Campusallee 12, 32657 Lemgo, Germany 


\section{Kognitive Kompatibilität in der variantenreichen Montage}

\section{Zusammenfassung}

Das Kompatibilitätskonzept findet in Psychologie und Ergonomie breite Verwendung. Es beschreibt die Passung zwischen Elementen eines soziotechnischen Systems und stellt die Voraussetzung für das erfolgreiche Zusammenwirken auf ein Systemziel hin dar. Von zunehmender Bedeutung ist die kognitive Kompatibilität. Sie beschreibt die Passung von extern präsentierter Information, ihrer internen Verarbeitung sowie der anschließend ausgelösten Arbeitshandlung. Mit zunehmender Komplexität nimmt die Wahrscheinlichkeit zu, dass es zu Inkompatibilitäten kommt, die zu Zeitverlusten, Fehlern und damit defizitärer Performanz führen. Gleichzeitig bedarf es eines höheren Aufwandes, kognitiven Inkompatibilitäten durch ergonomische Maßnahmen zu begegnen. Am Beispiel der variantenreichen manuellen Montage wird der Einsatz von informatorischen Assistenzsystemen in Verbindung mit ergonomischen Maßnahmen zur Informationspräsentation erörtert. Ziel ist es, kognitive Überforderungen im komplexen Montageprozess zu vermeiden. Herausfordernd ist hierbei vor allem die Passung zwischen extern vermittelter Arbeitsinstruktion und den individuell eingebrachten internen Modellen und Kompetenzen.

Praktische Relevanz: Die variantenreiche manuelle Montage erfordert ein hohes Maß an kognitiver Arbeit. Eine Zunahme der Komplexität der Montageaufgabe steigert das Risiko kognitiver Inkompatibilität, die sich in kognitiver Überlastung ausdrückt. Fallbeispiele zeigen, dass dieser Gefahr durch bessere Informationsdarbietung und durch den Einsatz von individuell anpassbaren informatorischen Assistenzsystemen begegnet werden kann.

Schlüsselwörter Kompatibilität · Mentale Modelle $\cdot$ Kognitive Beanspruchung · Variantenreiche Montage · Informatorische Assistenzsysteme

\section{Compatibility and information processing}

Compatibility research represents a traditional topic in psychology and ergonomics (Karwowski 2005). In psychology, this concept refers to the workplace specific stimulus-response patterns that must be designed and learned (Proctor and Reeve 1990). Compatibility must be consistent between what is required on the stimulus side and what has to be done on the response side. From an ergonomic point of view, the task is to find, practice, and permanently install exactly the coupling or correspondence in which an expected stimulus pattern triggers a desired reaction pattern as quickly, reliably, error-free as possible without overstressing the worker. The question arises, how e.g. signals and levers must be spatially arranged in relation to the employees' line of sight or how various symbols and texts must be prepared on a display streamlining the concrete work goal's efficiently realization. Designing specific working conditions that ensure a high correspondence of sensory uptake and motor response without exceeding the limits of strain on physical and mental structures in the stimulus-response mediation is a central aspect of ergonomics (Wickens 2008).

Over the past 70 years, information processing has been focused as a mediator of meaningful stimulus and selectable reaction patterns (Eberts and Posey 1990). For complex human-machine interaction tasks primarily aircraft, car, or train handling and cockpit design, as well as process control and monitoring tasks were analyzed. These tasks require extensive cognitive processing as a link between stimulus and response. In consequence, Wickens et al. (1983) developed their famous S-C-R compatibility approach. S-C-R-compatibility emphasizes the compatibilities between stimulus and central processes (S-C) and between central processes and responses (C-R). Tasks are performed quickly and errorfree if stimulus and reaction patterns are aligned with the relevant cognitive structures for information-processing. As such cognitive structures, attention, working memory, representational codes, and internal mental models were investigated intensively. Based on these investigations Hollnagel (1997) postulated cognitive ergonomics, which supplemented the traditionally more energetic or biomechanical ergonomics. The central task is to create the highest possible degree of cognitive compatibility between humans and work surrounding, especially in complex human-machine systems. With a focus on manual mixed-model assembly practical approaches will be presented in this article using informational assistance systems to reduce cognitive incompatibilities. Reduction can be achieved through supporting decision-making processes, avoiding individual uncertainty and mental overload, while increasing efficiency and overall product quality. Simon (1996), however, pointed out that ergonomics as a discipline only satisfices rather than optimizes which suggests that incompatibilities in more complex systems can probably not be completely eliminated.

\section{Compatibility research in Germany}

Helmut Strasser took up the concept of compatibility around the time of the publication of Proctor and Reeve 
(1990). In various publications of the 90es, he outlines compatibility in alignment with behavioristic positions as a stimulus-response (S-R) compatibility, to which he assigns patterns of compatible stimulus ( $\mathrm{S}-\mathrm{S})$ and equally compatible response (R-R) configurations. In his own work, he concentrates primarily on R-R compatibility, specifically on the correspondence of technical tools and anatomical structures like the hand-arm system. The merging and coexistence of suitably coordinated grip and hand structures ultimately result in a compatibility effect from which every performance benefits (Bullinger et al. 1987). For Strasser, however, this effect is less evident for fast and error-free work, but rather in the fact that employees are offered protection against health and safety impairments (Strasser 1994, 1995). Compatibility is therefore a central part of an occupational health and safety concept. Consequently, design and ergonomics must "follow the guideline that the human body is the ultimate standard" (Strasser 2009, p. 364).

This nuance strongly illustrates a more normative orientation. Strasser's compatibility concept is based on the idea of standardization. Just as the screw and the nut were made suitable worldwide by standardization (Strasser 2021, Fig. 1), technical tools and controls should generally be adapted to the human's anatomical conditions. "Similar to that technical compatibility (...) all technical elements and interfaces have to be designed in such a way, that they do not exceed human capacity in order to optimize human well-being and overall system performance" (Strasser 2021, p. 1). With this approach, Strasser goes well beyond the more efficiency-oriented view of Bullinger et al. (1987).

In cooperation with diverse organizations Strasser aimed and still aims to establish laws, rules, standards, guidelines, and user manuals. He wants to make sure "that the design of technical components of a work system according to human capacity (...) is viewed as the most important duty" (Strasser 2021, p. 4).

\section{Compatibility in the context of human factors ergonomics}

Strasser is primarily concerned with compatibility in the sense of congruence between technology's artificial and humans naturally predetermined anatomical structures. The latter are considered unchangeable, whereby compatibility loses the character of a general relation between two independent parts of a system that influence each other and work towards a common goal. However, it is precisely in this dynamic reciprocity that the appeal of compatibility lies in the socio-technical system. The pressure to adjust, as well as the adjustment itself, can emanate or be made by any element. On the one hand, this does not exclude ca- pacitive upper limits, but on the other hand, it also has the consequence that compatibility should not be understood as an unattainable ideal state but rather as a normal state in need of continuous improvement. This view, which is more oriented towards a dynamic interaction of elements, is further elaborated below with three focal points. Firstly, the relationship between the various S-S-, R-R- and S-R compatibilities is examined in more detail and the traditional S-R compatibility is brought back into the center of attention. Secondly, compatibility is not understood as a standardized state of only two elements but as the empirically determinable result of a variable and dynamic interaction of several, but at least two interdependently related elements in an observable process that is included in a goaloriented work system. Thirdly, cognition is also included in the S-R relationship which provides an additional starting point for compatibility, especially for internal mental processes (Wickens and Carswell 2021).

\subsection{Compatibility of stimulus and response patterns}

Compatibility describes an interactional relationship between units that are independent of each other, but nevertheless related to each other, and which cooperatively influence the achievement of goals and performance of an employee or a higher-level work system in an interactive process. Karwowski (2005) characterizes compatibility as a dynamic, natural phenomenon that is affected by the human-system structure, its inherent complexity, and its entropy or level of incompatibility between the systems elements. Lack of compatibility leads to a degradation of performance which is reflected in the systems measurable inefficiency and associated human losses. In this sense, compatibility represents a relational state between consecutive $\mathrm{S}$ - and R-patterns. Depending on the level of the selected man-made system, the design of a display, the equipment of a workplace, or the constellation of an assembly system can be regarded as a S-pattern. At the same time, R-patterns could consist, for example, in the selection of parts to be mounted, in the motion sequences during the assembly of a larger module, or in the overall assembly of a machine. In each case, the process represents a chain of many coupled S-R compounds, in which the controlled sub-target repeatedly becomes the starting point for further stimulation for successful task completion. Through the common goal, the different elements are related to each other in a relatively stable pattern and a dynamic compatibility relationship is created. 


\subsection{Compatibility as a feature of reciprocal dynamic adjustment}

In work systems, compatibility becomes a necessary condition of good performance but it is problematic to determine only an isolated fit-relationship between two of several interacting elements. Any compatibility between a pair of elements can be modified by a third element in a positive or negative direction. Compatibility thus becomes a feature of an interdependently ordered system, which expresses a cooperative rather than conflictual coexistence of at least two, usually more, independent elements in a targeted process. There is no standard for this. Where little compatibility is diagnosed in a social or socio-technical system, there is no integrative, goal-oriented cooperation. As a result, work processes run delayed and stressful. Existing incompatibility between elements of a system causes inefficiency of the entire system, unless it can be circumvented by compensatory measures that may generate additional costs.

Especially increasing complexity of work systems and processes raises the question of whether an ideal state of complete compatibility is achievable. Compatibility in one relation is often achieved at the expense of the compatibility in another relation. Each system consists of compromises between compatibility and incompatibility. Thus, the primary ergonomic goal would be to avoid a dysfunctional level of incompatibility. Increasing compatibility would become only secondarily important. In his CREAM approach (Cognitive Reliability and Error Analysis Method) Hollnagel (1998) uses the classifiers incompatible, compatible, and advantageous to describe the so-called quality of common working conditions, which signal unfavorable or favorable effects on performance. Compatibility in this method describes a satisfyingly normal value and not an ideal value. Even in the field of technology, optimal compatibility is unlikely to be achievable systemwide, because - in addition to high interindividual variability (also anatomically)—various influences can have reducing or increasing effects.

In his axiomatic approach for the ergonomic design of compatibility between process-relevant functional requirements and technological artifacts, Karwowski (2005) formulates two basic assumptions that support the previous considerations. The independence axiom describes a need for independence of functional requirements which are defined as the minimum set of independent requirements that constitute the design goal. The second assumption, the incompatibility axiom, stipulates a need for minimizing the incompatibility content of the design. The design that has the smallest incompatibility content or the smallest amount of incompatibility requirements concerning work processes is evaluated as the best design. Both assumptions imply that the mutual independence of many functionalities cre- ates incompatibility and that ergonomics must aim to minimize the extent of incompatibility between all elements. Both axioms indicate that incompatibility can be equated with entropy from an information-theoretical point of view. Entropy arises in increasingly complex systems, such as variant-rich mixed-model assembly. Drivers of this development are higher processual randomness and uncertainty with regard to the generated system states. This leads to delays and errors. However, the general solution to the problem of increasing incompatibility is not to reduce complexity, but to reduce the effort required for additional information processing (e.g. through improved instruction management or additional competence training). Thus, the final goal of ergonomics can only be to improve both the human and the system and their mutually dependent performance (Hancock 2017).

Interdependence and interaction of the individual functionalities towards the shared goal implies that in the event of incompatibility an attempt can be made to compensate for any deficits that occur. Compensation represents a targeted dynamic adjustment if despite anticipation the process gets out of the loop (as a precursor to error avoidance). However, compensation can only be provided temporarily because it is associated with physiological effort and organizational costs. Work systems differ according to how extensively they are prepared for such critical events and to which extend employees are willing to react flexibly in such crises. This brings dynamism into play, which compensates for deficits and ensures that the normally functioning interaction and the common orientation of all elements to the goal is relatively stable maintained. Prolonged disturbances in interaction require systematic ergonomic reorganizations.

\subsection{Cognitive compatibility as a fit between informational input, information processing, and motoric output}

Traditionally, ergonomics aimed at improving biomechanical relationships between external working conditions, technical artifacts, and human anatomical and biometric structures to eliminate existing incompatibilities. Only in the last four decades a variety of interdisciplinary efforts have been made to address mental states and processes in real work contexts and thus make them the subject of cognitive ergonomics (for a recent overview see Salvendy and Karwowski 2021). The physical stimulus becomes the information carrier and the motor reaction the result of a variety of information processing activities up to the final response control. Core concepts of this approach differ widely, including awareness, attention, decision-making, or mind, which also form starting points for cognitive engineering. "Cognitive ergonomics puts the focus on the way we think rather than the way we act, in particular on how 


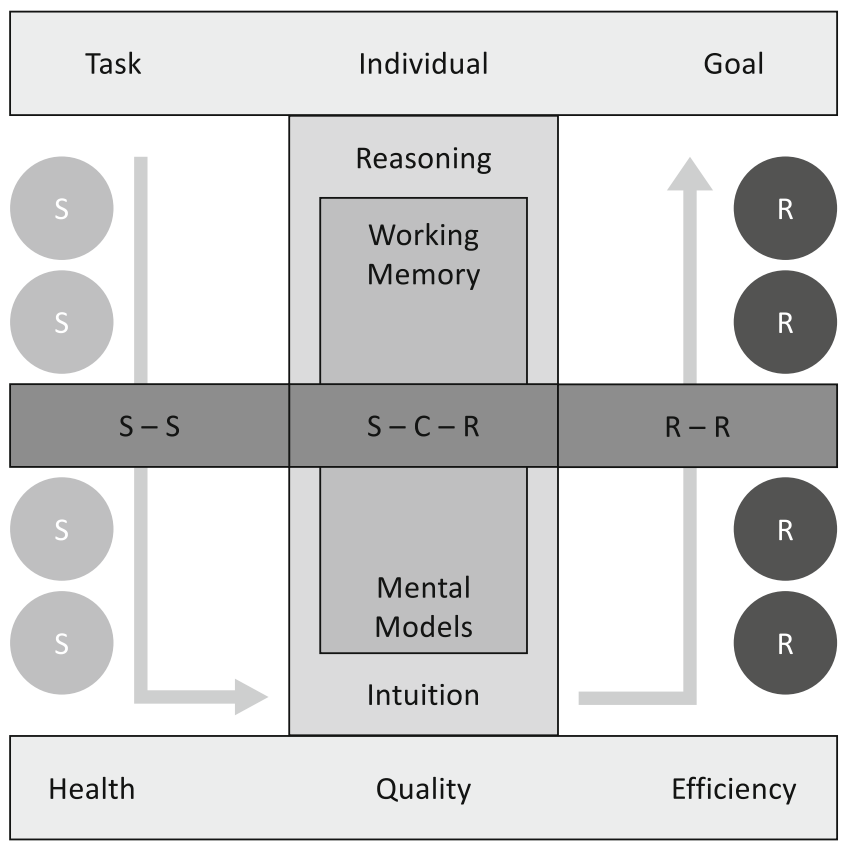

Fig. 1 Model of the cognitive mediation of stimulus and reaction patterns in the integrated work context which requires a co-functioning of various elements towards a common goal

Abb. 1 Mediation der Kognition auf Reiz-Reaktions-Muster im vernetzten Arbeitskontext mit dem Schwerpunkt auf der Kollaboration auf ein gemeinsames Ziel hin

people maintain control over their work" (Hollnagel 1997, p. 1173), where control at its core means cognitive control. In this approach, cognitive compatibility is aimed to create a fit between perceived requirements and cognitive structures, as well as these cognitive structures and (re-)actional performance. This is intended to contribute to an amplification of the human capability to perform cognitive work. The compatibility mechanism between sensory input and motor output therefore consists of a cyclic sequence and coupling of perceptual and action elements (Straeter 2008).

A currently discussed approach of neurocognitive ergonomics strives to make the underlying neurophysiological processes of every information processing observable and measurable, i.e. to show the coupling of cognitive processing and action in a direct way and to react ergonomically in real time (Parasuraman 2003, 2011; Dehais et al. 2020a).

Employees expended effort to achieve their work goal highly depends on the match and interaction of external information and internal processing structures (Hancock et al. 2021). Mental Workload is a variable "that attempts to quantify the extent of demands placed by a task on the mental resources we have at our disposal to process information" (Chen et al. 2016, p. 4). Simple work activities require little cognitive effort and lead to low workload. If the initial situation, e.g. in human-machine interaction, becomes more complex, the operators necessary cognitive processing increases too. In the first case-so the assumption-only a few intermediating cognitive steps between $\mathrm{S}$ and $\mathrm{R}$ are required, in more complex situations several additional steps or stages of internal information processing will take place. Hacker and Sachse (2014) characterize this sequence as action regulation. Such regulation includes necessary resources for all psychological processes from perception to motoric response. In addition, it is assumed that this regulation takes place with varying degrees of cognitive effort depending on task complexity (Rasmussen 1983). In the case of simple tasks, the coupling of $\mathrm{S}$ and $\mathrm{R}$ is habitual, fast, and less error-prone. In the case of complex tasks, it works slower, more deliberative, and more error-prone. Against this background, Kahneman (2012) distinguishes between a fast system 1 and a slower system 2. In parallel, Endsley (2000) speaks of intuition and reasoning.

A central aspect of cognitive processing is the operators internal or mental model of the system or the task, but it remains unclear where exactly such models are represented and structured, how they look like, and how they work (Eberts and Posey 1990; Bainbridge 1992). A comparison between momentary informational input and comparable past inputs is assumed as well as a subsequent selection of an action output (see Fig. 1). If the comparison is positive, the action selection takes place automatically and quickly (cognitive automation), if it is negative, more time is needed to select and decide as well as to plan the necessary steps to achieve the goal. Concerning the first case, Hacker and Sachse (2014) speak of a sensorimotor regulation, in the second case of a conceptual-perceptive regulation of action. Similarly, Rasmussen (1983) distinguishes between a simple skill-based and a more complex rule-based regulation. Both forms of regulation are each embedded in a profound, practice-oriented knowledge structure, which Kantowitz et al. (1990) describe as a contextually bound, meaningful frame.

There is currently no comprehensive psychological or ergonomic theory that depicts all aspects of internal mental models, their structures, and working methods. For example, Endsley (2000) focuses with the situational awareness theory on information extraction from the working environment, the integration of information in previous knowledge across different perceptual cycles in order to obtain a coherent picture, and to determine the use of these pictures in directing further perception and anticipating future events. It is therefore primarily about the formation, maintenance, and modification of a consistent theory. The goal is ultimately a valid internal model that is compatible with the external information and at the same time compatible with the action goal.

The role of intermediary cognitive processes has been recognized intensively by Wickens et al. (1983), who originally presented a model of Stimulus-Central Process- 
Fig. 2 Decision Ladder Model applicated to manual mixedmodel assembly (according to Rasmussen et al. 1994)

Abb. 2 Anwendung des Decision Ladder Models (nach Rasmussen et al. 1994) auf die variantenreiche manuelle Montage

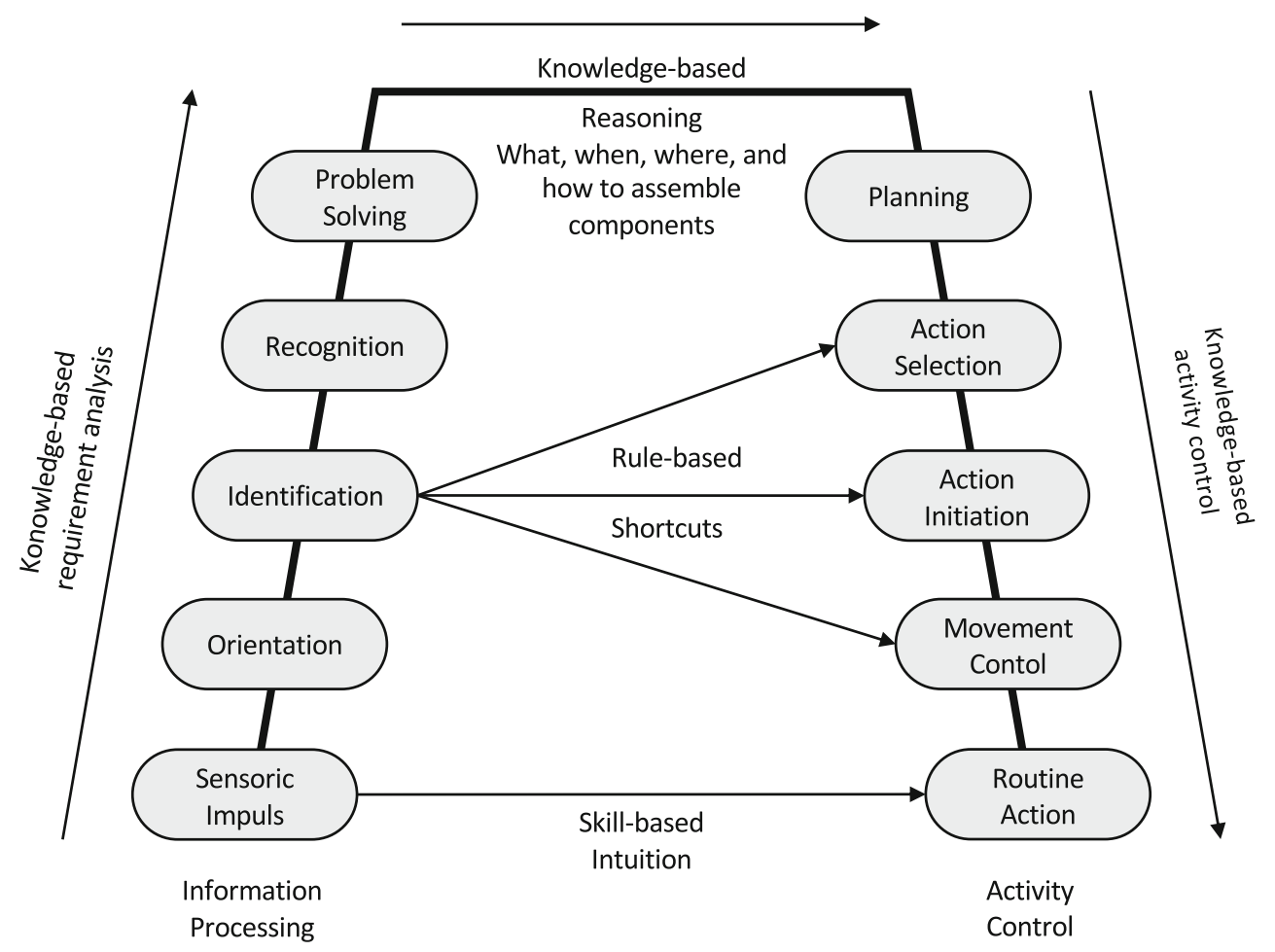

ing-Response compatibility. The S-C-R compatibility approach emphasizes compatibilities between the stimulus and a central processing unit and between the central processing unit and a concrete response. Although the authors postulate a central role of cognitive processing and mental models, they take a rather narrow view on this concept by examining only the code of mental model representation. Based on studies on operators' attention while piloting an aircraft, they developed the idea of multiple cognitive resource pools. It was found that auditorily heard and verbally encoded instructions as well as visually presented and spatially encoded information (arrangements of signals in the cockpit) pulled cognitive resources from different pools, which could be simultaneously tapped and better time shared than if the tasks requested resources only from the same pool (Wickens 2008). As a result of the positive relation between task performance quality and the amount of required resources, performance in high workload situations is dependent on the overall task structure and on the representation codices of the subtasks. High S-C and C-R compatibility result if tasks with verbal representation codes use speech as an input, while for tasks with a spatial representation the most compatible input is visual. Additionally, it was shown that verbal processing and speech output and spatial processing with manual output results in highest compatibility. The well-known Proximity Compatibility Principle refers directly to spatial representation: Information specification and execution of the task should be spatially close together (Wickens and Carswell 1995).
Mental models go far beyond representational codes (Bainbridge 1992). They are used to control behavior and to assist decision-making. The execution quality of separate complex tasks depends on how well the compatibility, in particular between real stimulus (displayed information) and the processed mental model as well as mental model and response selection, is designed. Incompatibility will result in additional mental transformations or decoding steps (which take time and cause errors) or even in confusion. This process is described particularly vividly in the socalled Decision Ladder Model by Rasmussen et al. (1994), as visualized in Fig. 2.

This model shows how-embedded in a comprehensive knowledge structure- a cognitive path is chosen from a given initial state to the execution of a response action. The input triggers decisions in ascending order (metaphorical one leg of an unfolded standing ladder), as to whether a specific rule of conduct fits the case that has occurred and whether a corresponding reaction should be triggered. In the most complex case, you have to climb to the top of the ladder and devise a new solution specially tailored to the present case (reasoning) and then implement it. In the simplest case, a skill-based rapid and intuitive implementation of the action and mastery of the task takes place in the shortest possible way without delaying decision-making. In between are rule-based procedures that are more or less abbreviations relative to the longest decision process.

The more rules to check, the longer the process takes, the more incompatibility there is between information dis- 
play and action. These findings are confirmed by Eberts and Posey (1990). The faster and more comprehensive rules are available or problem-solving paths with target hierarchies are present, the faster and more correctly the necessary reaction takes place.

Hollnagel (1998) approaches the problem on a comparable path, but backwards instead of forward. Where the traditional mechanistic view suggests analysis from the stimulus side, Hollnagel's CREAM approach takes the inverse path. It examines the S-C-R compatibility from the end and starts at the incorrect output of an action and searches for existing incompatibilities in profiles of cognitive demands that are pre-matched to the context. These can be an insufficient observation of the informational display, incorrect interpretation of signals, confusion due to too many simultaneously work steps, or high assembly part similarity. Insufficient performance is conceptualized as an outcome of an only deficiently controlled use of one's own competence concerning cognitive functions that prevents a favorable adaptation to the situational requirements. In this way, the detected error opens the window into the interior and provides a view of internal cognitive processes and incompatibilities: "Slips are the window to the mind" (Norman 1979 , p. 3). These errors can be linked to contextual factors, e.g. the instructional design or a display configuration. In this sense, errors in the area of action control are seen as the result of deficiencies in the cognitive system (e.g. lack of mastery of cognitive functionalities) or the working environment (e.g. bad light conditions), which both only allow cognitive control to a limited extent.

All four previously briefly described approaches have in common, that mindsets, mental states, and cognitive structures are important parameters for combining information from and directed response action to the environment. Thus, they determine the cognitive compatibility between input and output factors. Their constellation determines how the cooperation works normally and also in the event of a crisis and what adjustments and compensational efforts have to be achieved.

\section{Operationalization and measurement of cognitive compatibility}

Measurements of compatibility must always refer to an orderly constellation of system parts that correspond together in order to achieve a goal and overcome problems on the way to this goal. The concept of the joint cognitive system (Woods et al. 1987) expresses exactly this idea: The aim is to derive in a problem, not technology, -driven approach which additional tools could "help people function more expertly. (...) One must ask what aspect of the diagnostic performance of the current person-machine system is the bottleneck" (p. 158). Through ergonomic work on this bottleneck, it should ultimately be possible to ensure better performance. This performance can be observed and measured via various criteria such as assembly duration or number of errors. All measurements of observable behavior in the field of information reception, processing, and implementation can be understood as operationalizations of compatibility or incompatibility. Observed parameters are to be interpreted in comparison to specified times, quality standards, or norm values.

\subsection{Operationalization of cognitive incompatibility using time and error analysis}

Directly resulting from cognitive processing and actual performance time and error measures can be used to operationalize cognitive incompatibility. Their final, objective recording at the workplace usually raises only few measurement problems. For better processual understanding technology-based observations might be the more appropriate solution. Using either machine-data or data from motion capturing systems it is possible to detect even smallest delays and erroneous actions. Motion capturing can be used to investigate erroneous action tendencies (movement corrections) in the ongoing work process or to document strong interindividual fluctuations with regard to concrete movement sequences. Data gathered this way can not only reveal concrete incompatibilities but can also be used to derive concrete ergonomic countermeasures.

It remains relatively open whether detected incompatibilities between e.g. information structures and mental models are the only effective cause of loss of time and quality. Finally, there is a great uncertainty in the determination of the absolute magnitude of incompatibility, because time and error analysis can only be conducted against predetermined limits. In timeline analysis, quotients are formed from time required to time available. The less time (with higher availability) is required, the more information processing resources remain unused and the lower the resulting incompatibility turns out.

\subsection{Operationalization via physiological indicators and biomarkers}

Modern physiological measurement instruments open up further possibilities to operationalize cognitive incompatibility via physiological parameters or biomarkers, for example in the case of high mental workload (Bläsing and Bornewasser 2020). With the help of technically sophisticated and mobile measuring instruments, continuous, noninterruptive, and non-invasive measurements are possible directly at the workplace and in work processes. 
Using eye-tracking and gaze behavior as methods for incompatibility detection, it is possible to observe patterns of pupil dilatations, eye movements, and fixation durations over a human-machine work cycle (Bläsing and Bornewasser 2021). So-called Areas of Interest analyses can be used to determine which elements of the workplace are fixated, how often, and for how long, in order to obtain the necessary information in a short time or to exercise action control. Such analyses can help to identify sources of distraction and to derive appropriate ergonomic measures.

The mindless human factor ergonomics has now become an increasingly mindful one using "machines for minds" (Christensen 1987, p. 6). This trend is supported by the increasing effort to analyze brain activities during the work process and thus to determine the way how the brain with its limited capacity works when people work. The central mediating factor is, again, the concept of mental workload. Instead of time and errors, (neuro-)physiological biomarkers can be used to operationalize compatibility or incompatibility as measurable workload changes (Parasuraman and Rizzo 2008; Matthews et al. 2015). Spatial and temporal resolution of these methods have been increasingly improved in recent years. Thus, with regard to cognitive processing an increasingly accurate picture emerges of which physiological process takes place at which time and in which area as well as even at increasingly identifiable cells and nerve fibers.

Dispositional constructs such as attention, workload, or compatibility cannot be directly measured but be inferred. Using measurement techniques with high temporal and spatial resolution so-called neuroergonomists take an alternative path aiming to record neurophysiological states directly by means of so-called brain-based metrics to directly determine their causal influence. The theoretical prerequisite for this is to not longer record brain processes and states via insufficiently operationalized dispositional constructs, but to show direct results of biochemical reactions and transmissions in selected pathways. Dehais et al. thus emphasize a "shift from limited cognitive resources to characterizing impaired human performance and associated states with respect to neurobiological mechanisms" (2020b, p. 2). The prerequisite for this is to further improve the measurement technology. The overarching goal of neuroergonomics is - and this is probably what authors around Ayaz and Dehais (2021) are primarily concerned with-to design neuroadaptive technology to monitor mental states and to trigger appropriate cognitive countermeasures to mitigate the deleterious effects on human performance (Dehais et al. 2020a). Such countermeasures should help to overcome satiation, to mitigate poor decision making, to stimulate neurological activity, and finally even to reallocate tasks of operator and machine. Decisive for such projects are less theoretical concerns (Hancock 2019) and more technical feasibility.

\section{Informational assistance in mixed-model assembly}

Mixed model assembly requires high levels of adaptability to changing working conditions with a low level of stability between different assembly models. With increasing number of to be assembled products and product variants, as a result of increasing entropy, information density and uncertainty increase too. This leads to an overall increase in incompatibility. Karwowski (2005, p. 456) describes this connection as the complexity-incompatibility principle: "As the (artefact-human) system complexity increases, the incompatibility between the system elements (...) also increases, leading to greater ergonomic (non-reducible) entropy of the system and decreasing the potential for effective ergonomic intervention". This implies a high mental workload, and increases the probability of absent-mindedness, mistakes, and action slips (Reason and Mycielska 1982) and therefore a loss of time and quality. Current complexity drivers are the high number of different, and at the same time similar, parts, the high dynamics of changes in individual products during their life cycle, and the high number of additional special assembly operations (software installation, product markings, etc.) (Bornewasser et al. 2018). In this context, empirical studies point to a variety of deficits in the informational design of complex manual assembly systems (Claeys et al. 2015), which lead to frequent task interruptions, search processes, or consultations, e.g. with designers. All that signals insufficient system compatibility.

\subsection{Sources of incompatibility in modern manual assembly}

According to Hollnagel (1998) workers characteristics like competence or attention are not the main cause of incompatibility. Potential sources are in the deficient design of work environments, technical equipment, and information displays. Designers have insufficient theories and ideas of workers cognitive processing and cognitive control, leading to incompatibilities between technical artefacts, including information management, and human internal models of the task. Thus, in order to avoid difficulties, it seems necessary to develop theories, concepts, and instructions that might be in better harmony with cognitive theories.

A first consequence of this approach is to develop better information management, which has to be adjusted to the workers' mental models. It is not enough to call for information, that is accurate, complete, current, timely, relevant, and which is communicated through the proper information 
Fig. 3 Increasing the fit between instruction mode and worker's internal mental model leads to increased compatibility and decreased working memory load Abb. 3 Eine Verbesserung der Passung zwischen der Arbeitsanweisung und mentaler Modelle der Beschäftigten führt zu einer Steigerung der Kompatibilität und einer Reduktion der Beanspruchung des Arbeitsgedächtnisses

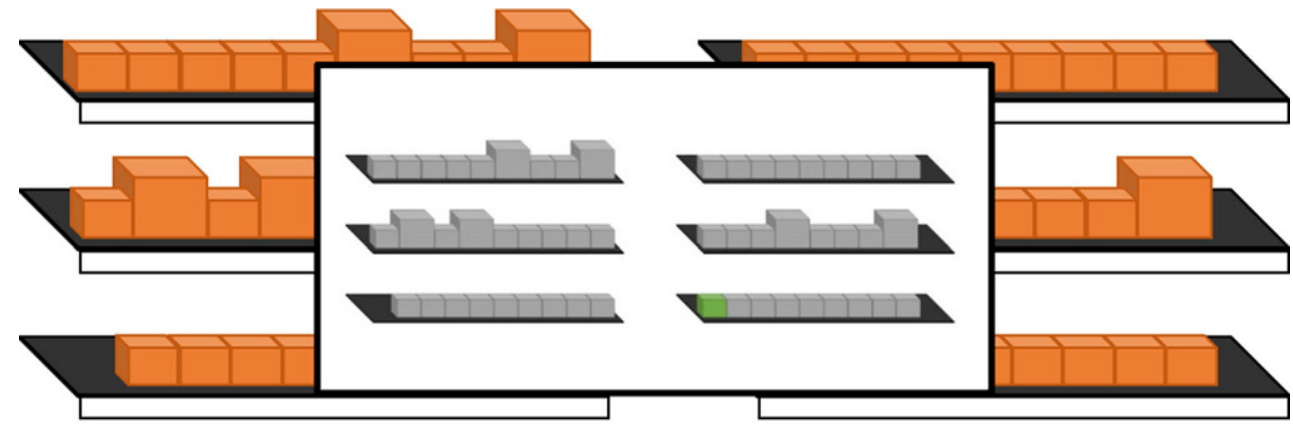

Pick-By-Picture Design

carrier on a correct detailed level for the intended receiver with an unquestionable clarity (Beynon-Davies 2013). What is additionally necessary is to ensure that each of these attributes is tailored to the information processing of the individual employee. What is current or relevant must be defined in the eyes of the individual worker and the individual possibilities to control the performance in the given context. An error-free and clearly designed CAD construction sketch does probably not meet the informational needs of the assembly employee. Likewise, the usage of rather abstract article numbers for assembly parts (taken from the internal ERP system) may not be the most sufficient way to display the location information. Examples show that cognitive compatibility might conflict with organizational, i.e. hierarchical, compatibility. From an organizational point of view, CAD sketches and article numbers are an important prerequisite for the effectiveness and efficiency of the entire organization, their use in the context of assembly instructions usually leads to incompatibilities. A second consequence of Hollnagel's approach is closely connected: There is a need for better, early employee participation, starting in the process of assembly planning. Using this participatory approach, many factors can be identified in advance to avoid efficiency losses (Imada 1991).

\subsection{Approaches to avoiding incompatibilities in assembly}

Based on the complexity-incompatibility principle (Karwowski 2005), incompatibilities in assembly can be avoided by reducing or better mastering complexity:

- The reduction strategy aims to simplify and standardize processes and to routinize and decognitize work activities. In the age of industrially oriented individual assembly, the possibilities of this approach are limited. Although there are considerable efforts, for example in the field of product modularization or the implementation of the principles of Design for Assembly (Boothroyd et al. 2011), a strategic reorientation of production, as a result of the globalization of networked markets, increasing customization, and rapidly growing digitization could not be prevented.

- The mastery strategy is based on the idea of explicitly recognizing complexity, but limiting it in terms of its harmful effects and maintaining a balance of intuition and reasoning through improved tools for establishing higher S-C-R compatibility (Wickens et al. 1983). The core of this strategy implies assembly assistance systems, which concern the S-C area and thus the information acquisition and processing, but also the $\mathrm{C}-\mathrm{R}$ area and thus the competence-based behavior control. From a cognitive ergonomic point of view, such technical devices could temporarily organize some kind of task reallocation by taking over partial actions of the worker at short notice.

Facing increases of mental workload, assistance systems support through cognition amplification, i.e., strengthening the possibilities to perform demanding cognitive activities and to stretching the limits of adaptability, such as supporting the information intake process through better chunking to exhaust the magic limit of 7 plus 2 bits of information (Miller 1956) or supporting the choice process despite a high number of alternatives. Wickens (1987) already re-

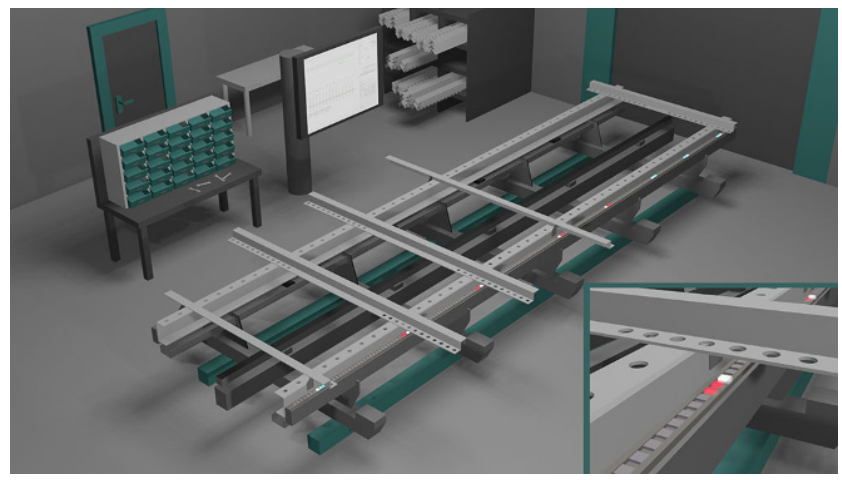

Fig. 4 Integrated information management systems reduce operator choice complexity, ease decision making, and increase S-R compatibility

Abb. 4 In den Arbeitsablauf integrierte informatorische Assistenzsysteme sorgen für eine Reduktion der Auswahlkomplexität, erleichtern das Treffen von Entscheidungen und erhöhen die S-R-Kompatibilität 
Matrix representation of assembly workstation before partitioning

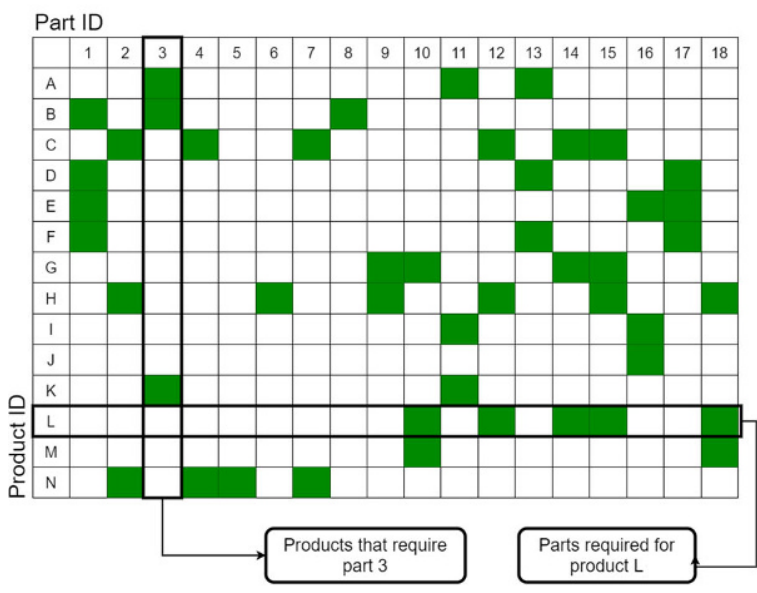

Matrix representation of assembly workstation after partitioning into two modules

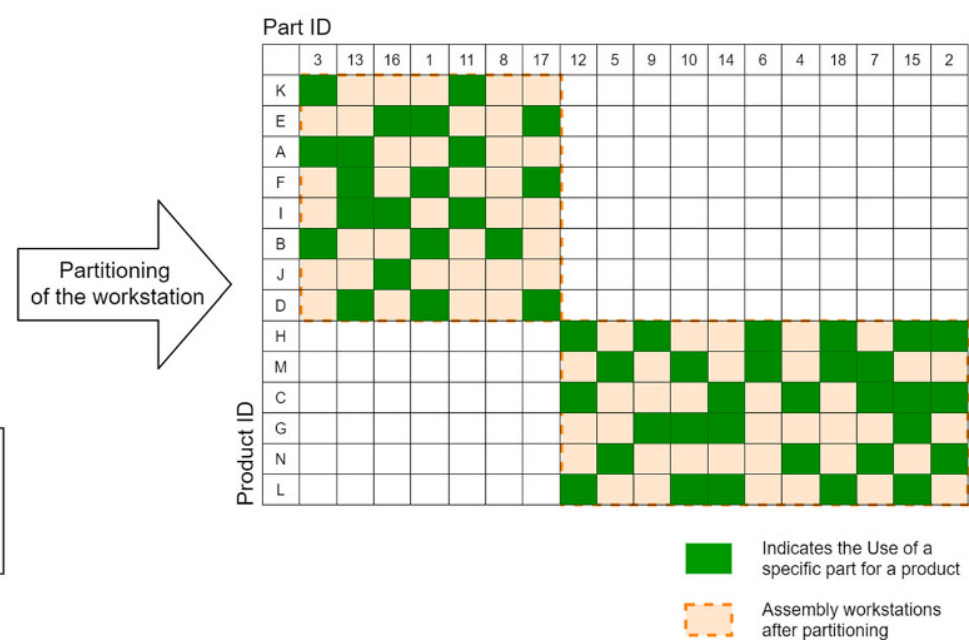

Fig. 5 Process optimization and attentional guidance (accompanied by a high level of intuitiveness) increases compatibility and productivity Abb. 5 Prozessoptimierung und Aufmerksamkeitslenkung (einhergehend mit einer Erhöhung der intuitiven Nutzbarkeit) sorgen für einen Anstieg von Kompatibilität und Produktivität

ferred to three major areas of possible support: Working memory limitations (Fig. 3), decision-making (Fig. 4), and attention (Fig. 5). Exemplary results from the project "Montexas4.0" are reported as three use cases, showing the influence of incompatibility reduction on different aspects of modern manual assembly.

Optimizing the workflow to reduce mental workload, prevent working memory overload, and triggering system 1 usage is a valuable situational prevention strategy. In the first use case the design of the assembly parts supply system was changed based on the usage of approaches with less informational load. The standard 10-digit system (imported from purchasing) was compared to a 3-digit, 1-digit, and a Pick-by-Picture $(\mathrm{PbP})$ system. 3- and 1-digit solutions where further supported by a color and shape aid. The $\mathrm{PbP}$ system indicated the location of the part to be picked using a green highlight on a simplified graphical representation of the assembly station. Complexity assessments, workload, and mean picking time were compared over all four approaches indicating that the fastest picking time, least complexity and workload were achieved using the $\mathrm{PbP}$ approach (Fig. 3). Based on data of 20 participants the raw NASA Task Load Scores of the 10-digit and the $\mathrm{PbP}$ system revealed a difference of 33 points (48 and 15 ). Increased practical relevance can be shown comparing the mean picking times of $22.10 \mathrm{~s}$ against $4.45 \mathrm{~s}$ per part in favor of the $\mathrm{PbP}$ approach. 3- and 1-digit solutions still outperformed the 10-digit solution and might be an easier to implement alternative to the $\mathrm{PbP}$ solution. $\mathrm{PbP}$ tends to maximize the cognitive compatibility for the human operator directly highlighting the position of the part that needs to be picked (e.g. highlighted container). Thus, this strategy can be used to reduce operator's mental workload while at the same time reducing picking times by an incompatibility reduction.

Informational assistance systems in manual assembly help to reduce mental workload through increasing compatibility between individual cognitive prerequisites and task demands. Following this approach, in the second use case a digital Put-to-Light system was developed, indicating where and how to assemble different parts of a truck support framework using the place and color of the light as cues for specific assembly parts (Fig. 4). The overall reduction of information load can help to increase compatibility. While cognitive load reduces, human performance (speed and accuracy) increases, thus increasing the overall productivity. In this use case the task-specific digital assistance system contributed to more compatibility in three ways: 1) Getting users included into the design process through means of participatory ergonomics and consider their cognitive processes; 2) Reducing the amount of unnecessary displayed information and increasing the fit between users internal models and presented informational cues through a new Put-to-Light approach; 3) Offering individual configuration possibilities of the assistance system concerning details like color-schemes, font-sizes, or different point-ofviews for the assembly object.

The third use case focuses on the reduction of operator choice complexity through proximity optimization of the assembly part distribution. The main driver of increasing complexity of modern manual assembly is the high number of different models to be assembled at one working station. This variety makes it necessary to store assembly parts of all models at the same working station. As a consequence, 
operator choice complexity as well as incompatibility are increased. In order to increase compatibility and to reduce search times and error probabilities, low physical distance between part containers should reflect cognitive proximity. Following a logic similar to Hebb's Law (cells that fire together wire together) parts that are usually used in the same models should be located close to each other. Using different optimization algorithms, a restructuring and size reduction of a manual assembly station was achieved (Fig. 5; Sehr and Moriz 2019). The increased compatibility between the operator's expectation of where to find the following assembly part and the physical location increased the overall performance at this working station.

All these measures can be used to enable the mastery of complexity in the manual mixed-model assembly. The main purpose of such measures can be described as getting the right amount of information in the right format and bringing it to the right person at the right time (Johansson et al. 2017). This presupposes that the shown capacity limits in the reception of information are observed and that incompatibilities between demand and resources are avoided as far as possible. And it must also be ensured that workers' internal mental models of the concerning task structure, the assembly processes, and the required cognitive performance are compatible with the tasks requirements. This is the only way to ensure that the worker not only sees and reads provided data structures, but also understands the information contained in them and derives the right behavioral consequences. This requires a high degree of informational compatibility between supply and demand structures. Woods et al. (1987, p. 1749) point out that "aiding human cognitive performance requires description of application-specific cognitive activities". Such descriptions are reflected in cognitive task analysis by Rasmussen (1986) and Hollnagel (1998). Cognitive task analysis serves to ensure that employees have an accurate mental model of the system and can readily assimilate present information in their own model (Norman 1986). Informational assembly assistance systems therefore aim to act as a compatibility enabler by matching the stimulus and reaction patterns to the workers' cognitive structures in line with the S-C-R approach. Mattsson and Fast-Berglund (2016) formulate similar guidelines for a compatibility-promoting information presentation: Support active cognitive processes, mental models, abilities and limitations, individual preferences, placement of information, and intuitiveness. The final ergonomic goal is always to improve compatibility by better designing the information input, the information processing and decision-making structures, and last but not least the performance conditions.

\subsection{Compatibility between assistance system and individual user}

According to Genaidy et al. (2007) work compatibility is defined as a function of energy expenditure of different environmental elements that interact with the person, simultaneously taking or providing energy. Therefore, each assistance system also represents an element of the system, which in combination with other compatible elements contributes to the joint success. The ergonomic goal of the work compatibility model is to identify those elements in the work environment that contribute to good performance and decide which elements require intervention. This raises the question of information display design relative to the experience and internal requirements of the persons involved. Four aspects are important here:

\section{Selection of output devices and design of assembly in- structions}

In mixed-model assembly varying input and output devices with different information interfaces are used. Depending on various factors different assistance systems are possible, like permanently installed or mobile tablet solutions, head-mounted displays or AR glasses that are only worn and used as required, or projection-based assistance (Hinrichsen et al. 2020). Empirical studies show that the acceptance and use of support systems depend to a large extent on the perceived usability of the individual devices, which in turn are moderated by the previous experience of the employees. For example, the use of a familiar medium such as a tablet in laboratory tests led to shorter training and execution times compared to data glasses (Bendzioch et al. 2020).

Informational assembly assistance systems act as external information stores that compensate for potential working memory deficits. Designing those systems, it is important to find the right fit between necessary information from the designers and workers point of view and to integrate them in an intuitive way. Important features of processing are listed by Helander (1987): Information should attract attention via prominence, novelty, and relevance (conspicuity and important parts of necessary information should be emphasized). Important requirements for the selection of information concern the intelligibility, timeliness, completeness, and standardization of information. With these requirements, the challenge arises that a dynamical adaptation to the different qualifications and previous experience must be possible to consider inter-individual informational needs. Otherwise, every assembly instruction loses its usefulness, is perceived as disturbing, and is no longer accepted (Bornewasser et al. 2018). A pragmatic implementation of this concept can be achieved, by offering 
short and long forms of assembly instructions, by allowing the employee to decide autonomously when support systems are switched on or off, or by offering the choice between image- and text-based instructions (Hinrichsen 2020). What seems to be most important: Reducing ambiguity, simplifying instructions, and making them more accessible, i.e. suitably tailored to internal models of the recipient.

2. Assembly assistance systems as part of an integrated operational information management

In the future, assembly instructions for individualized, customer-specific products will be generated more and more (partially) automatically and be provided digitally. The basis for such automated instruction creation are the ERP system based order data, data of the associated digital product model (digital twin), and characteristics of the individual assembly worker. Such an integration of an assembly assistance system into the existing IT infrastructure will contribute to the design of end-to-end digital value chains as a vision of Industry 4.0 (Hinrichsen et al. 2017). These chains include data on strengths and weaknesses of individual assembly employees (e.g. need of text in larger font due to visual impairment), as well as data concerning previous experience with individual product types. Data will be the basis for individualization of assembly instructions and a mean to avoid incompatibilities.

3. Systems for error detection and process optimization

Even if assembly instructions are designed according to requirements and suitable input and output devices are selected, assembly errors can still occur due to distraction, carelessness, or concentration problems of the employee. Such human deficits can be compensated by adding functions of error detection and real-time process optimization to the assistance system, e.g. via automatic visual inspection (Beyerer et al. 2012). For particularly quality-critical assembly steps, test characteristics can be defined in the software of the image processing system. In combination with machine learning, errors can be recognized and disturbances, fluctuations, and dispersion of execution times in the assembly process are automatically identified. Additionally, the assistance system could provide the employee with suggestions for a suitable configuration of the software on the basis of his degree of practice (e.g. concerning execution times for partial tasks). As a result, there is more compatibility between type and scope of the information output and workers' individual needs. Feedback from employees, for example on insufficient assembly part arrangements or unsuitable representations in automatically generated assembly instructions, can lead to improved information assistance systems as well as improved/re-designed work places.

\section{Training of competences}

Intelligent and interactive support systems are also used to build up employee's competencies through training on the job (Bornewasser and Kloyer 2018). In this way, personnel deficits that cause incompatibility are eliminated. The aim of such programs is to become self-modifying and generative, i.e. to change itself over a longer phase of interactive learning processes (and for example to set increasingly difficult tasks or to reduce the amount of instruction) and thus to make itself adaptable. Eberts and Brock (1987) outline some of the building blocks of such programs that are still current today with regard to content and their implementation in learning instructions. These comprise, for example, the coordination of learning objectives with individual differences regarding learning strategies of experts and novices in the field or the design of continuous or distributed feedback processes that indicate to workers with as short time delays as possible that goals have been achieved or not achieved. So-called augmented feedback can already be used in the course of task processing, e.g. by only reinforcing individual sub-steps in practice phases or by projecting alarming signals onto the screen in the event of deviations (Hancock 1996; Dehais and Ayaz 2019). In addition, individual sub-steps can be subjected to targeted practical exercises instead of the entire course of action, all of which serve to increase routine.

\section{Conclusion}

Cognitive ergonomics is becoming increasingly important in individualized production and assembly. Especially with an increasing demand for adaptability, agility, and flexibility in the work process, it is essential to extend the idea of compatibility to the relationship between information intake, processing, and concrete labor action and to understand cognition as an important, if not central, element to ensure the smooth interaction of these factors towards the shared goal. The cognitive side allows for more plasticity and adaptability compared to the physical side. For companies, the task is to push cognitive compatibility in the narrower sense, with regard to assistance systems used in mixed-model assembly. It is crucial to align the overall situation, not just selected individual relationships, with ergonomic compatibility (Young et al. 2015). Two aspects have to be kept in mind: With increasing complexity, compatibility of the overall system is becoming increasingly remote.

Despite all the technical support, work should remain human-centered (Hacker and Sachse 2014), i.e. even with increasing cognitive stress, all support should only be of- 
fered in the sense that the worker remains autonomous and has the ability to finally decide about how the assembly takes place. A non-consensual automatic replacement, in the sense of an automatic takeover, in the presence of specific physiological patterns (Dehais et al. 2020b) should be out of question. What is already technically feasible, e.g. in the context of military actions, should not be the benchmark for industrial assembly work.

Funding Open Access funding enabled and organized by Projekt DEAL.

Open Access This article is licensed under a Creative Commons Attribution 4.0 International License, which permits use, sharing, adaptation, distribution and reproduction in any medium or format, as long as you give appropriate credit to the original author(s) and the source, provide a link to the Creative Commons licence, and indicate if changes were made. The images or other third party material in this article are included in the article's Creative Commons licence, unless indicated otherwise in a credit line to the material. If material is not included in the article's Creative Commons licence and your intended use is not permitted by statutory regulation or exceeds the permitted use, you will need to obtain permission directly from the copyright holder. To view a copy of this licence, visit http://creativecommons.org/licenses/by/4. $0 /$.

\section{References}

Ayaz H, Dehais F (2021) Neuroergonomics. In: Salvendy G, Karwowski W (eds) Handbook of human factors and ergonomics, 5th edn. Wiley, New Jersey, pp 816-841

Bainbridge L (1992) Mental models and cognitive skill: the example of industrial process operation. In: Rogers Y, Rutherford A, Bibby PA (eds) Models in the mind: theory, perspective and application. Academic Press, London, San Diego, pp 119-143

Bendzioch S, Bläsing D, Hinrichsen S (2020) Comparison of different assembly assistance systems under ergonomic and economic aspects. In: Ahram T, Karwowski W, Pickl S, Taiar R (eds) Advances in intelligent systems and computing. Human systems engineering and design, vol II. Springer, Cham, pp 20-25

Beyerer J, Puente León F, Frese C (2012) Automatische Sichtprüfung. Springer, Berlin, Heidelberg

Beynon-Davies P (2013) Business information systems, 2nd edn. Palgrave Macmillan, New York

Bläsing D, Bornewasser M (2020) Influence of complexity and noise on mental workload during a manual assembly task. In: Longo L, Leva MC (eds) Human mental workload: models and applications. Communications in computer and information science. Springer, Cham, pp 147-174

Bläsing D, Bornewasser M (2021) Influence of increasing task complexity and use of informational assistance systems on mental workload. Brain Sci 11:102

Boothroyd G, Dewhurst P, Knight WA (2011) Product design for manufacture and assembly, 3rd edn. CRC Press, Boca Raton

Bornewasser M, Kloyer M (2018) Prozessintegriertes und austauschbasiertes Kompetenzmanagement. In: Bornewasser M (ed) Vernetztes Kompetenzmanagement. Kompetenzmanagement in Organisationen. Springer, Berlin, Heidelberg, pp 93-105

Bornewasser M, Bläsing D, Hinrichsen S (2018) Informatorische Assistenzsysteme in der manuellen Montage: Ein nützliches Werkzeug zur Reduktion mentaler Beanspruchung? Z Arbeitswiss 72:264-275
Bullinger H-J, Kern P, Muntzinger W (1987) Design of controls. In: Salvendy G (ed) Handbook of human factors. Wiley, New York, pp 577-600

Chen F, Zhou J, Wang Y, Yu K, Arshad SZ, Khawaji A, Conway D (2016) Robust multimodal cognitive load measurement. Springer, Cham

Christensen JM (1987) The human factors profession. In: Salvendy G (ed) Handbook of human factors. Wiley, New York, pp 3-16

Claeys A, Hoedt S, Soete N, Van Landeghem H, Cottyn J (2015) Framework for evaluating cognitive support in mixed model assembly systems. IFAC-Pap 48:924-929

Dehais F, Ayaz H (2019) Progress and direction in neuroergonomics. In: Ayaz H, Dehais F (eds) Neuroergonomics. The brain at work and in everyday life. Academic Press, London, San Diego, pp 3-7

Dehais F, Karwowski W, Ayaz H (2020a) Brain at work and in everyday life as the next frontier: grand field challenges for neuroergonomics. Front Neuroergonomics 1:583733

Dehais F, Lafont A, Roy R, Fairclough S (2020b) A neuroergonomics approach to mental workload, engagement and human performance. Front Neurosci 14:268

Eberts RE, Brock JF (1987) Computer-assisted and computer-managed instruction. In: Salvendy G (ed) Handbook of human factors. Wiley, New York, pp 976-1011

Eberts RE, Posey JW (1990) The mental model in stimulus-response compatibility. In: Advances in psychology. Elsevier, Amsterdam, pp 389-425

Endsley MR (2000) Theoretical underpinnings of situation awareness, a critical review. In: Endsley MR, Garland DJ (eds) Situation awareness analysis and measurement. Lawrence Erlbaum, Mahwah, pp 1-24

Genaidy A, Salem S, Karwowski W, Paez O, Tuncel S (2007) The work compatibility improvement framework: an integrated perspective of the human-at-work system. Ergonomics 50:3-25

Hacker W, Sachse P (2014) Allgemeine Arbeitspsychologie: psychische Regulation von Tätigkeiten vol 3. Hogrefe, Göttingen

Hancock PA (1996) Effects of control order, augmented feedback, input device and practice on tracking performance and perceived workload. Ergonomics 39:1146-1162

Hancock PA (2017) Mind, machine and morality. CRC Press, Boca Raton

Hancock PA (2019) Neuroergonomics: where the cortex hits the concrete. Front Hum Neurosci 13:115

Hancock GM, Longo L, Young MS, Hancock PA (2021) Mental workload. In: Salvendy G, Karwowski W (eds) Handbook of human factors and ergonomics, 5th edn. Wiley, New Jersey, pp 203-226

Helander MG (1987) Design of visual displays. In: Salvendy G (ed) Handbook of human factors. Wiley, New York, pp 507-548

Hinrichsen S (2020) Informatorische Gestaltung der Montage mittels Assistenzsystemen. In: Bornewasser M, Hinrichsen S (eds) Informatorische Assistenzsysteme in der variantenreichen Montage. Springer, Berlin, Heidelberg, pp 21-42

Hinrichsen S, Riediger D, Unrau A (2017) Development of a projection-based assistance system for maintaining injection molding tools. In: 2017 IEEE International Conference on Industrial Engineering and Engineering Management (IEEM). IEEE, Singapore, pp 1571-1575

Hinrichsen S, Adrian B, Bornewasser M (2020) Information management strategies in manual assembly. In: Ahram T, Taiar R, Gremeaux-Bader V, Aminian K (eds) Advances in intelligent systems and computing. Human interaction, emerging technologies and future applications, vol II. Springer, Cham, pp 520-525

Hollnagel E (1997) Cognitive ergonomics: it's all in the mind. Ergonomics 40:1170-1182

Hollnagel E (1998) Cognitive reliability and error analysis method: CREAM, 1st edn. Elsevier, Oxford, New York

Imada AS (1991) The rationale and tools of participatory ergonomic. In: Noro K, Imada AS (eds) Participatory ergonomics. Taylor \& Francis, London, pp 30-51 
Johansson PEC, Enofe MO, Schwarzkopf M, Malmsköld L, FastBerglund A, Moestam L (2017) Data and information handling in assembly information systems - a current state analysis. Procedia Manuf 11:2099-2106

Kahneman D (2012) Thinking, fast and slow. Penguin Books, London

Kantowitz BH, Triggs TJ, Barnes VE (1990) Stimulus-response compatibility and human factors. In: Advances in psychology. Elsevier, Amsterdam, pp 365-388

Karwowski W (2005) Ergonomics and human factors: the paradigms for science, engineering, design, technology and management of human-compatible systems. Ergonomics 48:436-463

Matthews G, Reinerman-Jones LE, Barber DJ, Abich J (2015) The psychometrics of mental workload: multiple measures are sensitive but divergent. Hum Factors 57:125-143

Mattsson S, Fast-Berglund $\AA$ (2016) How to support intuition in complex assembly? Procedia Cirp 50:624-628

Miller GA (1956) The magical number seven plus or minus two: some limits on our capacity for processing information. Psychol Rev 63(2):81-97

Norman DA (1979) Slips of the mind and an outline for a theory of action. Defense Technical Information Center, Fort Belvoir

Norman DA (1986) New views of information processing: implications for intelligent decision support systems. In: Hollnagel E, Mancini G, Woods DD (eds) Intelligent decision support in process environments. NATO ASI Series. Springer, Berlin, Heidelberg, pp 123-136

Parasuraman R (2003) Neuroergonomics: Research and practice. Theor Issues Ergon Sci 4:5-20

Parasuraman R (2011) Neuroergonomics: brain, cognition, and performance at work. Curr Dir Psychol Sci 20:181-186

Parasuraman R, Rizzo M (2008) Neuroergonomics: the brain at work. Oxford University Press, New York

Proctor RW, Reeve TG (1990) Research on stimulus-response compatibility: toward a comprehensive account. In: Advances in psychology. Elsevier, Amsterdam, pp 483-494

Rasmussen J (1983) Skills, rules, and knowledge; signals, signs, and symbols, and other distinctions in human performance models. IEEE Trans Syst Man Cybern 13:257-266

Rasmussen J (1986) A framework for cognitive task analysis in systems design. In: Hollnagel E, Mancini G, Woods DD (eds) Intelligent decision support in process environments. NATO ASI Series. Springer, Berlin, Heidelberg, pp 175-196

Rasmussen J, Pejtersen AM, Goodstein LP (1994) Cognitive systems engineering. Wiley, New York

Reason JT, Mycielska K (1982) Absent-minded? the psychology of mental lapses and everyday errors. Prentice-Hall, Englewood Cliffs
Salvendy G, Karwowski W (eds) (2021) Handbook of human factors and ergonomics, 5th edn. Wiley, New Jersey

Sehr P, Moriz N (2019) Partitioning manual assembly workstations for flexible manufacturing. In: 2019 24th IEEE International Conference on Emerging Technologies and Factory Automation (ETFA). IEEE, Zaragoza, pp 102-109

Simon HA (1996) The sciences of the artificial, 3rd edn. MIT Press, Cambridge

Straeter O (2008) Cognitive parameter for the relationship of situation awareness and behaviour. Z Arb Wiss 63:45-54

Strasser H (1994) Reducing prevalence of occupational diseases and physiological costs by obeying the rule of compatibility in work design. In: Aghazadeh F (ed) Advances in industrial ergonomics and safety VI. Taylor \& Francis, London, pp 151-158

Strasser H (1995) Kompatibilität als Ziel der ergonomischen Arbeitsgestaltung von Mensch-Maschine-Systemen. Zentralbl Arbeitsmed Arbeitsschutz Ergonomie 45(1):6-21

Strasser H (2009) Principles, methods and examples of ergonomics research and work design. In: Schlick CM (ed) Industrial engineering and ergonomics: visions, concepts, methods and tools. Springer, Berlin, Heidelberg, pp 363-381

Strasser H (2021) Compatibility as guiding principle for ergonomics work design and preventive occupational health and safety. Z Arb Wiss. https://doi.org/10.1007/s41449-021-00243-0

Wickens CD (1987) Information processing, decision making and cognition. In: Salvendy G (ed) Handbook of human factors. Wiley, New York, pp 72-107

Wickens CD (2008) Multiple resources and mental workload. Hum Factors 50:449-455

Wickens CD, Carswell CM (1995) The proximity compatibility principle: its psychological foundation and relevance to display design. Hum Factors 37:473-494

Wickens CD, Carswell CM (2021) Information processing. In: Salvendy G, Karwowski W (eds) Handbook of human factors and ergonomics, 5th edn. Wiley, New Jersey, pp 114-158

Wickens CD, Sandry DL, Vidulich M (1983) Compatibility and resource competition between modalities of input, central processing, and output. Hum Factors 25:227-248

Woods DD, O'Brien JF, Hanes LF (1987) Human factors challenges in process control: The case of nuclear power plants. In: Salvendy $G$ (ed) Handbook of human factors. Wiley, New York, pp 1724-1770

Young MS, Brookhuis KA, Wickens CD, Hancock PA (2015) State of science: mental workload in ergonomics. Ergonomics 58:1-17 